\title{
Detecting regional variability in sources and sinks of carbon dioxide: a synthesis
}

\author{
A. J. Dolman ${ }^{1}$, C. Gerbig ${ }^{2}$, J. Noilhan ${ }^{3}$, C. Sarrat ${ }^{3}$, and F. Miglietta ${ }^{4}$ \\ ${ }^{1}$ VU University Amsterdam, Department of Earth Sciences, Boelelaan 1085, 1081 HV Amsterdam, The Netherlands \\ ${ }^{2}$ Max Planck Istitute for Biogeochemistry, Hans-Knoell-Str. 10, 07745 Jena, Germany \\ ${ }^{3}$ Météo France, CNRM_GMME 42, avenue G. Coriolis, 31057 Toulouse, France \\ ${ }^{4}$ Institute of Biometeorology, National Research Council (IBIMET-CNR), Via Caproni, 8-50145 Firenze, Italy
}

Received: 22 December 2008 - Published in Biogeosciences Discuss.: 24 February 2009

Revised: 29 May 2009 - Accepted: 2 June 2009 - Published: 17 June 2009

\begin{abstract}
The current paper reviews the experimental setup of the CarboEurope Experimental Strategy (CERES) campaigns with the aim of providing an overview of the instrumentation used, the data-set and associated modelling. It then assesses progress in the field of regional observation and modelling of carbon fluxes, bringing the papers of this special issue into a somewhat broader context of analysis.
\end{abstract}

Instrumental progress has been obtained in the field of remotely monitoring from tall towers and the experimental planning. Flux measurements from aircraft are now capable, within some constraints, to provide regular regional observations of fluxes of $\mathrm{CO}_{2}$, latent and sensible heat.

Considerable effort still needs to be put into calibrating the surface schemes of models, as they have direct impact on the input of energy, moisture and carbon fluxes in the boundary layer. Overall, the mesoscale models appear to be capable of simulating the large scale dynamics of the region, but in the fine detail, like the precise horizontal and vertical $\mathrm{CO}_{2}$ field differences between the models still exist. These errors translate directly into transport uncertainty, when the forward simulations are used in inverse mode. Quantification of this uncertainty, including that of inadequate boundary layer height modelling, still remains a major challenge for state of the art mesoscale models. Progress in inverse models has been slow, but has shown that it is possible to estimate some of the errors involved, and that using the combination of observations. Overall, the capability to produce regional, high-resolution estimates of carbon exchange, exist in potential, but the routine application will require considerable effort, both in the experimental as in the modelling domain.

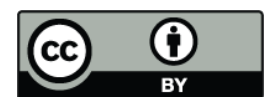

Correspondence to: A. J. Dolman (han.dolman@geo.falw.vu.nl)

\section{Introduction}

The determination of sources and sinks of $\mathrm{CO}_{2}$ from the terrestrial surface is fraught with difficulties. At small scale, local measurements with eddy covariance towers can indicate a net sink or source (Dolman et al., 2008), at large, continental scale the "inverse" method determines sources and sinks of $\mathrm{CO}_{2}$, albeit with substantial uncertainty (Stephens et al., 2007). How to link the two methods is subject of an active and growing area of investigations (e.g. Gerbig et al., 2009). The linkage between the local and regional to continental scale is non trivial, however, understanding of the processes involved at this scale change is key to improving our capability to determine sinks and sources with reduced uncertainty and at high resolution. Reducing the uncertainty is important to allow credible assessments of emissions and uptake that are relevant to climate treaties such as UNFCCC (United Nations Framework Convention on Climate Change). Reducing the scale is critically important to understand the absolute variation in source and sink strength and attribute specific processes to particular regions, or land use management systems.

At the regional, sub continental scale, loosely defined here as areas of a few hundred kilometres wide and long, $\mathrm{CO}_{2}$ injected in the lower atmosphere becomes subject to flow patterns that are sub-grid in the sense of current weather forecasting and climate models. The use of observations to constrain estimates of sources and sinks by inverse methods (e.g. Gurney et al., 2002) through inverse models at continental scale is then subject to errors involving representativeness and aggregation and these need to be quantified. Also, increasing the resolution of the source and sink estimates, requires high-resolution observations and flow patterns to be established. How to determine these, and how to establish the required limit of our observational and modelling capacity is largely unknown.

Published by Copernicus Publications on behalf of the European Geosciences Union. 
These flow patterns can only be represented by the new generation of mesoscale models (Pielke et al., 1992; Nicholls et al., 2004; Denning et al., 2003). Van der Molen and Dolman (2006) were among the first to use these models to address the problems involved in deriving meaningful area mean values of $\mathrm{CO}_{2}$ concentration for a spatially heterogeneous area. They showed that mesoscale topographical effects in Central Siberia induced significant perturbations in the mean concentration field that would have to be taken into account when using locally observed concentration values in inversion studies. The perturbations were also visible in the experimental record. From a preliminary analysis on current stations of the global monitoring network they concluded that more than $50 \%$ of those stations could be subject to regional or mesoscale perturbations caused by topography or sea breezes. Further studies (Ahmadov et al., 2007; Sarrat et al., 2007a) corroborated this view and showed that seabreezes and other meso-scale flows affected the mean concentration and induced significant representation errors (Tolk et al., 2008). Ahmadov et al. (2007) suggested that these spatial effects should be treated similarly to the diurnal and seasonal rectification effects (Denning et al., 1996) in largescale inversions and suggested to call them 3-D rectification effects. Common practice in large scale inversions is to select the data from continuous monitoring stations around noon, so as to suffer little from any mesoscale of diurnal rectification effects. How to extract the correct data when spatial rectification effects occur is less obvious, and would probably depend very strongly on the conditions surrounding the local and regional monitoring site. The complex diurnal concentration patterns that arise from these mesoscale circulations remain however a potential large source of information on the fluxes of the surrounding area, and it is a major challenge to retrieve that information (e.g. Gerbig et al., 2009).

Several experiments in the last few years have started to address the regional spatial variation of atmospheric $\mathrm{CO}_{2} \mathrm{ex}-$ perimentally to determine the spatial distribution of sources and sinks. Examples are the $\mathrm{CO}_{2}$ Budget and Rectification Airborne study (COBRA; Gerbig et al., 2003) and the Cooperative LBA Airborne Regional Experiment (LBA-CLAIRE98; Andrea et al., 2002). Gioli et al. (2004), Schmitgen et al. (2004), and Vila-Guerau et al. (2004) describe elements of several of these pilot experiments in Europe. Gerbig et al. (2003) report that at scales starting around $10-30 \mathrm{~km}$ significant atmospheric $\mathrm{CO}_{2}$ variations occur, and that these need to be represented accurately when using the concentration profiles and transects to infer fluxes. These experiments suggested that regionally large concentrations gradients develop that can only be observed with high accuracy measurements and be only meaningfully interpreted with high resolution transport models.

Based on experience from these experimental and modelling studies, the regional experiment CERES (CarboEurope Regional Experiment Strategy, Dolman et al., 2006) was planned to combine various types of ground-based carbon cycle-related measurements and atmospheric observations with remote sensing to infer a regional carbon budget. The original aim was to derive a regional scale carbon budget at $2 \mathrm{~km}$ resolution for about 20 years. This goal was very ambitious but the project effectively set some major steps towards that goal by executing a series of field experiments and by using and improving mesoscale models for estimating fluxes and transport. The current paper briefly reviews the experimental setup of the CERES campaigns with the aim of providing an overview of the instrumentation used and of the data-set. It then tries to assess progress in the field of regional observation and modelling of carbon fluxes, thus bringing the papers of this special issue into a more coherent context of analysis. We finish with a set of recommendations for work that remains to be done before the overall aim of a developing region carbon data budgeting system can be achieved.

\section{Experimental set-up}

The methodology of CERES consisted of making concentration measurements both within and above the boundary layer and to couple those via a modelling/data assimilation framework to the flux measurements at the surface and within the boundary layer. To achieve this, we instrumented a region near the Landes forest with ground- and air-based measurements at high spatial and temporal resolution. This area was chosen because of the wealth of supporting data that exist from the previous HAPEX-MOBILHY experiment (André et al., 1986) and the vicinity of Météo-France in Toulouse with state-of-the-art forecasting tools.

The experimental domain covers an area of about $250 \mathrm{~km} \times 150 \mathrm{~km}$ in southwest France (Fig. 1). It is bounded to the west by the Atlantic Ocean, the shoreline being almost rectilinear along a north-south orientation. The western half of the domain is dominated by the Landes forest, of which $80 \%$ is included in the Regional Experiment area. The forest is mainly composed of maritime pine (Pinus pinaster Ait.). There are clearings of various size, which contain agricultural land, mainly maize, but also grassland and pasture (in the southern part of the forest), or other cultivars like vegetables. Elsewhere in the domain, the land is covered by cereals, such as maize, with the exception of the Garonne River valley (crossing the domain from southeast to northwest) where there are fruit trees and winter crops, and the large "Bordeaux" vineyards, east and northwest of Bordeaux city. There are mostly winter crops towards the southeast, whereas summer crops increase toward the Landes forest. The northeast corner is a vast, little-cultivated region, mainly composed of woods and pastures. Two major cities are located close to the southeast (Toulouse) and northwest (Bordeaux) corners of the domain. The Landes forest and the valley of the Garonne River are relatively flat areas, whereas the rest of the domain is mainly composed of gentle hills. Outside the domain, to the south, the Pyrénées mountain range 


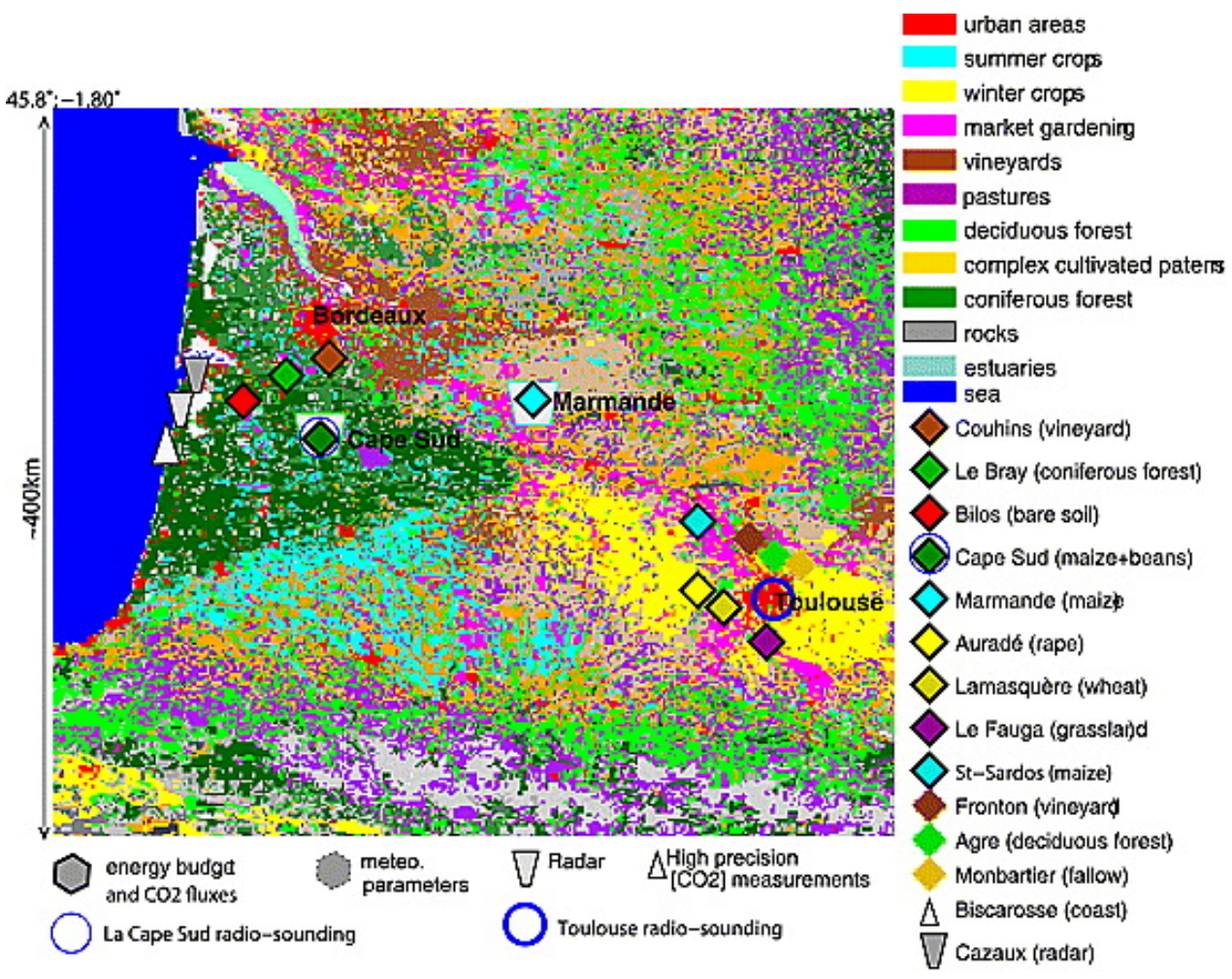

Fig. 1. Map of surface vegetation cover over the CERES domain with experimental network (grey squares are flux stations).

presents a solid west-east barrier rising occasionally above 3000-m height. This has a strong influence on the generation of local winds in the domain.

A set of ground-based surface flux measurements, regular radio-soundings, determining the profiles of temperature, humidity and wind speed through the atmosphere, and wind and temperature profilers for the lowest few hundred meters of the atmosphere were installed (details can be found at http:// carboregional.mediasfrance.org/experiment/index). Aircraft measurements with low flying flux aircraft were also performed. Boundary layer sampling with small aircraft took place and long transects were flown with aircraft sampling concentrations of $\mathrm{CO}_{2}$ and various other trace gasses (see Dolman et al., 2006 for an extensive description of the the first campaign). Three campaigns were executed to sample the seasonal variation of activity of the land surface from 16 May to 25 June 2005 and in April and September 2007. The previously executed experiments essentially indicated that to be able to retrieve a full regional scale carbon not only a set of observations needs to be available to be assimilated in to a model, but that also some extra observations need to be available for validation of estimates. Several of the flux towers and aircraft data served this purpose.

Table 1 gives an overview of the experimental activity of these campaigns. The 2007 experimental set-up differs from the 2005 one. In the 2007 case, the CERES 2005 measurements have been completed by $\mathrm{CO}_{2}$ concentration observation from a tall tower of $60 \mathrm{~m}$ height (BellegardeSaint-Marie's tower, near Toulouse), in addition to the Biscarosse and Marmande towers.

Eight surface stations were measuring continuously the $\mathrm{CO}_{2}$ and energy surface fluxes, at representative ecosystems of the region (pine forest, young tree, 2 maize, grassland, sunflowers, wheat, fallow). Radio-soundings were launched during Intensive Observation Periods (IOP) days in Toulouse in April and in September in Toulouse and at La Cape Sud (the central site in the Landes forest, already installed in 2005).

Three aircraft, the Dimona (MetAir) and two Sky Arrows (IBIMET and ALTERRA) were flying over the Landes forest or near Toulouse during IOP days when the meteorological conditions were favourable. The second and third campaign took place in April (from the 18th to the 23rd for 6 days continuously and during 8 days in September (7-8 and from the 10 th to the 15 th. 
Table 1. Observations made during the three CERES campaign.

\begin{tabular}{|c|c|c|c|}
\hline Types of Observations & May-June 2005 & April 2007 & September 2007 \\
\hline Number of IOP days & 22 days & 6 days & 8 days \\
\hline \multirow[t]{2}{*}{$\mathrm{RS}$} & $128 \mathrm{RS}+11 \mathrm{BVC}$ & $19 \mathrm{RS}$ & $22 \mathrm{RS}$ \\
\hline & Toulouse + La Cape Sud & Toulouse & Toulouse + La Cape Sud \\
\hline \multicolumn{4}{|l|}{ Piper-Aztec: } \\
\hline$\left[\mathrm{CO}_{2}\right] \&$ dynamic & 23 flights & 0 & 0 \\
\hline Dimona: & 10 flights & 3 flights South & 3 flights South \\
\hline$\left[\mathrm{CO}_{2}\right] \&$ dynamic & & 8 flights Landes & 8 flights Landes \\
\hline $\begin{array}{l}\text { Sky Arrow Ibimet } \\
\text { Flux measurements }\end{array}$ & 52 flights & 11 flights & 4 days of measurements \\
\hline $\begin{array}{l}\text { Sky Arrow Alterra } \\
\text { Flux measurements }\end{array}$ & 0 & 11 flights & 7 days of measurements \\
\hline Sky Arrow Isafom & 15 flights & 0 & 0 \\
\hline \multirow[t]{2}{*}{$\mathrm{CO}_{2}$ conc. towers } & 2 & 3 & 3 \\
\hline & Biscarosse, Marmande & $\begin{array}{l}\text { Biscarosse, Bellegarde, } \\
\text { Marmande }\end{array}$ & $\begin{array}{l}\text { Biscarosse, Bellegarde, } \\
\text { Marmande }\end{array}$ \\
\hline Flux Stations & 10 & 8 & 8 \\
\hline
\end{tabular}
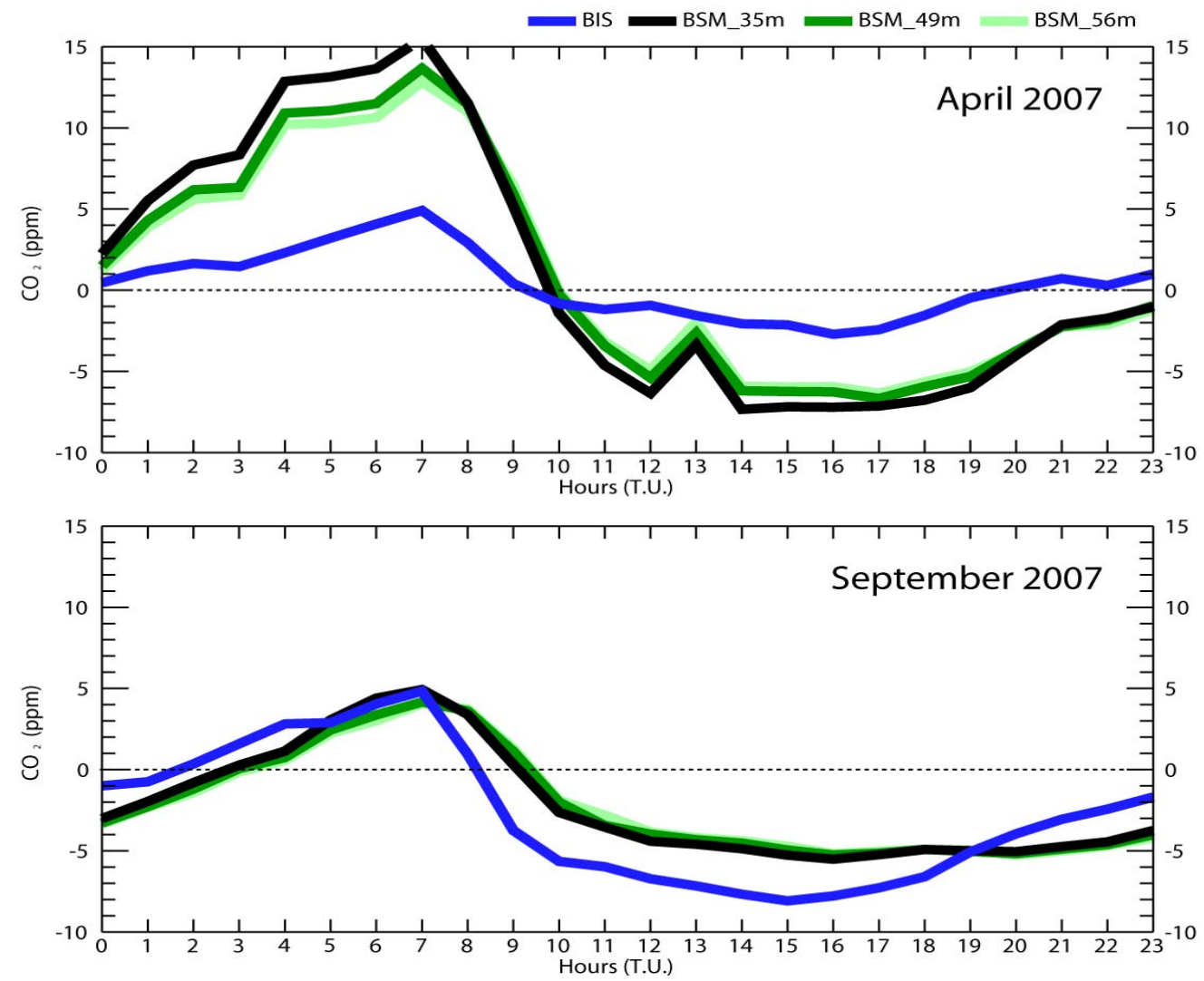

Fig. 2. Mean $\mathrm{CO}_{2}$ concentration measured at the Biscarosse tower (blue) and at the Bellegarde-Sainte-Marie tower at different height (green and black), during the April (above) and September (below) 2007 campaigns (data provided by LSCE). 

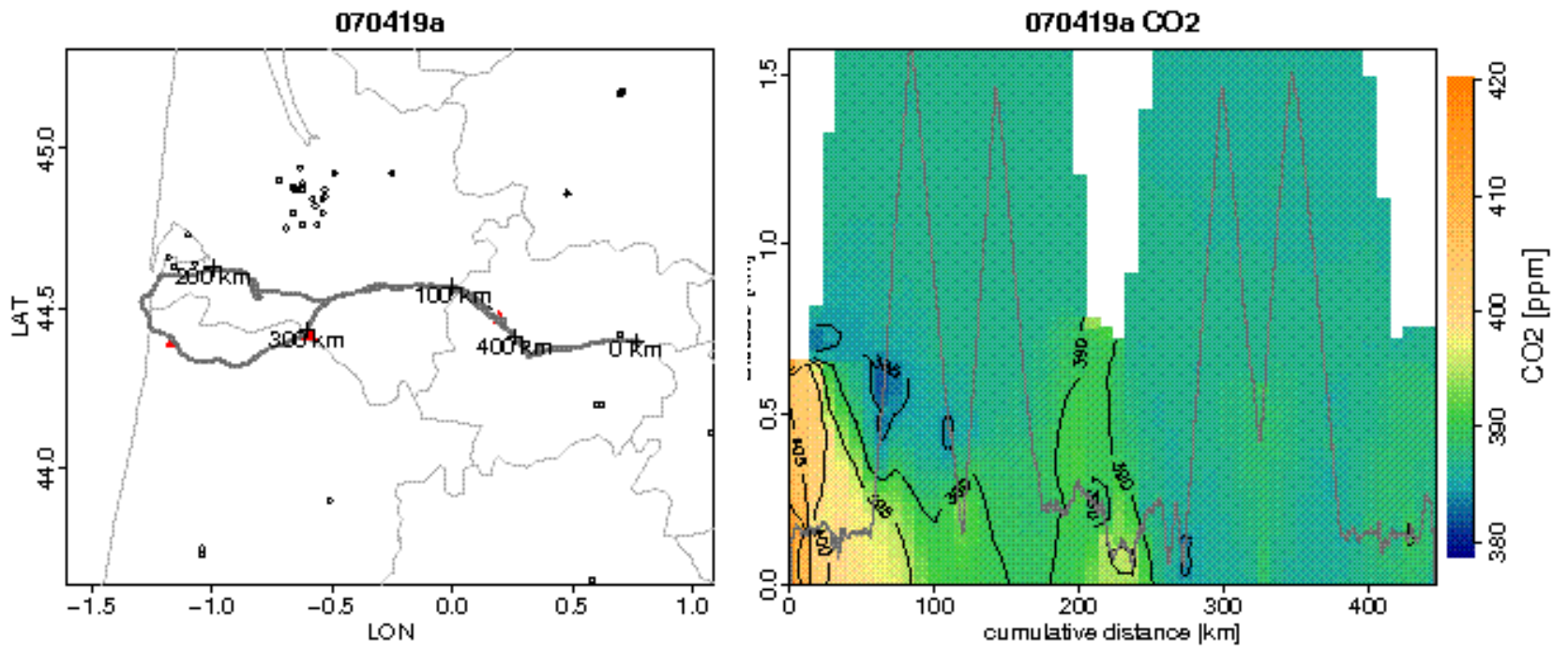

Fig. 3. Dimona aircraft trajectory (left) on 19 April 2007 over the croplands, the Landes forest and the ocean, and the vertical cross section of the $\mathrm{CO}_{2}$ concentration measured as the function of the distance flown by the aircraft (right).

\section{Progress in instrumental deployment and experiment planning}

Although several of the techniques used for observing fluxes and $\mathrm{CO}_{2}$ concentrations were used in earlier experiments and form part of the CarboEurope or FLUXNET network (e.g. Jarosz et al., 2009), we highlight here five areas of development that represent significant progress compared to these previous experiments.

First, in addition to the single high precision observation "tall" tower at Biscarosse on the coast, of the 2005 campaign, we operated a second tower near the town of BellegardeSainte-Marie, more inland, in the two 2007 campaigns. Both towers contained a CARIBOU instrument, a Non Dispersive Infra-Red spectrometer developed at CEA, Paris, France. The system is based on a modified commercially available LI-6262 infrared gas analyzer, but is capable of remote operation, sending data through a (mobile) phone line.

The accuracy of the CARIBOU instrument is approximately $0.02 \mathrm{ppm}$ (RMS). The availability of these instruments represents a major step in our capability to remotely observe and control high accuracy measurements of $\mathrm{CO}_{2}$ concentrations.

As an example of the data, Fig. 2 shows the diurnal cycle of the measurements at the two towers, with a $\mathrm{CO}_{2}$ maximum observed during the night due to the accumulation of $\mathrm{CO}_{2}$ in the night-time boundary layer as a result of anthropogenic and biospheric emissions. At Bellegarde the diurnal cycle is much more pronounced in April (22 ppm vs $10 \mathrm{ppm}$ ) than in September. This is most likely due to strong diurnal land uptake through biospheric activity in April linked to a higher LAI compared to September, but also to a strong nocturnal respiration due to the soil water content, higher in April than in September, that could favour a higher soil microbiological activity. The diurnal pattern of $\mathrm{CO}_{2}$ at Biscarosse shows less seasonal variation, as it is more influenced by the $\mathrm{CO}_{2}$ from the marine sources. The amplitude of the diurnal cycle at Biscarosse is higher in September compared to April (13 ppm vs. $8 \mathrm{ppm}$ ), as a result of the summer photosynthetic activity of the Northern hemisphere.

Second, the concentration observations made from towers were complimented by observations made from aircraft platforms. In the first campaign a Piper Aztec (PA23-250) and a DIMONA (Met Air, Switzerland, http://www.metair. $\mathrm{ch} /$ SYSTEMS.htm) were flown together, in 2007 we flew only the DIMONA. Both aircraft used a modified LI-6262 for $\mathrm{CO}_{2}$ concentrations, while the DIMONA also used an open path LICOR 7500 and sampled flask for a posteriori calibration. The accuracy of these instrument setups is $0.2 \mathrm{ppm}$, making it possible to detect small gradients in the boundary layer.

The use of these aircraft measurements, although not completely novel, in both vertical and horizontal profiling makes it possible to detect regional patterns (Dolman et al., 2006; Ahmadov et al., 2007) and to validate predictions of mesoscale models (Sarrat et al., 2007). In 2007, the Dimona flew (Fig. 3) over the western part that revealed an east-west $\mathrm{CO}_{2}$ gradient with higher values at low levels over the crops and the Landes forest than near the ocean coast. Most of the flights show that this gradient remains in the afternoon, although the regional differences are reduced because of the boundary layer vertical mixing. Higher values of $\mathrm{CO}_{2}$ concentrations over land at this time of the year is probably related to relatively high value of soil respiration (wet conditions), low value of $\mathrm{CO}_{2}$ uptake and reduced vertical mixing in the atmospheric boundary layer. 
Third, flux measurements from aircraft were obtained with two Sky Arrow 650 ERA's (Environmental Research Aircraft). The SkyArrow is a commercially produced, certified small aircraft equipped with sensors that measure three dimensional wind and turbulence together with gas concentrations and other atmospheric parameters at high frequency. The aircraft has a cruise flight speed of $45 \mathrm{~m} \mathrm{~s}^{-1}$ with an endurance of $3.5 \mathrm{~h}$, allowing it to cover flight distances of up to $500 \mathrm{~km}$. Operating altitudes can range from $10 \mathrm{~m}$ above ground level to more than $3500 \mathrm{~m}$ above sea level (Gioli et al., 2006).

The aircraft hosts the Mobile Flux Platform (MFP), which consists of a set of sensors for atmospheric measurements. The actual wind components (horizontal U, V and vertical $\mathrm{W})$ relative to the ground are calculated introducing corrections for three-dimensional velocity, pitch, roll and heading of the aircraft using a combination of GPS velocity measurements and data from two sets of three orthogonal accelerometers mounted at the centre of gravity of the aircraft and in the centre of the hemisphere. Eddies of wavelengths larger than $1.4 \mathrm{~m}$ can be detected. The probe is equipped with a fast thermocouple to measure air temperature with a response time of $0.02 \mathrm{~s}$. A platinum resistance thermometer is used for a mean air temperature reference. For CO2 a LI-7500 is used positioned on the top of the nose of the aircraft.

In April 2007, the Sky Arrow IBIMET flew horizontal transects in the western part of the domain, the measurement methodology is described by Miglietta et al. (2009). Figure 4 shows the fluxes of sensible and latent heat and $\mathrm{CO}_{2}$ observed at $100 \mathrm{~m}$ above ground by the aircraft observations. One can note the systematically high value of $\mathrm{CO}_{2}$ uptake by $\mathrm{n}$ the northwestern section of the transect whereas the $\mathrm{CO}_{2}$ flux over the forest is relatively weak. The latent heat flux is relatively high due to large water availability in the soil following a prolonged rainy period

Fourth, availability of a considerable amount of experimental data has made it possible to add complementary experiments to the existing efforts, such as shown by Rascher et al. (2009). They performed additional airborne measurements of solar induced fluorescence in combination with extensive ground-based quantification of leaf- and canopylevel processes in support of ESA's Candidate Earth Explorer Mission, FLEX. During three measurement periods in 2007 structure and functional characteristics over 20 different types of vegetation in the Landes region were extensively characterized. On the larger spatial scale, the aim of this campaign was to test if fluorescence can be detected from airborne platforms and if this remote sensing signal can be used to improve estimates of plant mediated exchange on the mesoscale. For that purpose canopy fluorescence was quantified from three airborne platforms: (I) a hyperspectral spectrometer that was installed on the Dimona delivered fluorescence in the oxygen A band along transects during 12 day courses, (II) the prototype airborne sensor AirFLEX was installed in a twin engine aircraft (Piper Seneca
III) quantified fluorescence in the oxygen A and B bands and (III) the first employment of the high performance spectroimager SIM.GA HYPER (Galileo Avionica, Firenze, I), a $512+256$-spectral-band push-broom sensor with VNIR and SWIR imaging capability which delivered spatially resolved and multi-temporal transects across the whole region. Additionally, high resolution geolocated hyperspectral data cubes along the whole optical spectrum, including the thermal region were gathered with theAirborne Hyperspectral Scanner (AHS) which is an 80-bands airborne imaging radiometer (SensyTech Inc.). Both sensors were operated jointly in a C-212-200 airplane operated by the Spanish Institute for Aerospace Technology (INTA) Several transects and flight lines were successfully recorded during the three measurement periods.

Finally, as mentioned in the introduction the location of the experiment was chosen because of the wealth of previous data on land cover, soils and the possibility to use the mesoscale forecasting system of CNRM to plan the experiment. Using forecasted meteorological fields from the operational mesoscale model ALADIN the Stochastic Time Inverted Lagrangian Transport model (STILT, Lin et al., 2003) was used for planning the aircraft operations, as it provided every day for several routine meteorological forecast estimates of the source region of particular observation patterns. This made the planning of flights considerable more reliable and accurate.

\section{Progress in modelling}

\subsection{Forward modelling}

The focus on the regional scale calls for assessing the performance of the current generation of mesoscale models to simulate adequately the transport mechanisms at meso-beta (sea-breeze, topographically induced flow) and meso-gamma (flux heterogeneity, boundary layer cloud) scale. During the project we used three different mesoscale models, The French, Meso-NH system, the Regional Atmospheric Modelling System (Pielke et al., 1992) and the Weather Research and Forecasting (model WRF; Skamarock et al., 2005). Ultimately one would be able to use the transport of the mesoscale models in backward models to calculate the regional sources and strengths. To be able to do that first the capability of the current models needs to be assessed against the observational data obtained during the campaigns.

Early modelling results of the CERES 2005 campaign were compared and analysed by Sarrat et al. (2007b). They compared five different meso-scale models with various settings and versions to see how they represented the evolution of the atmospheric carbon dioxide fields. To some extent, this intercomparison provided the starting point and benchmark for the modeling aspects of CERES. The complex spatial distribution as well as the temporal evolution of $\mathrm{CO}_{2}$ in 

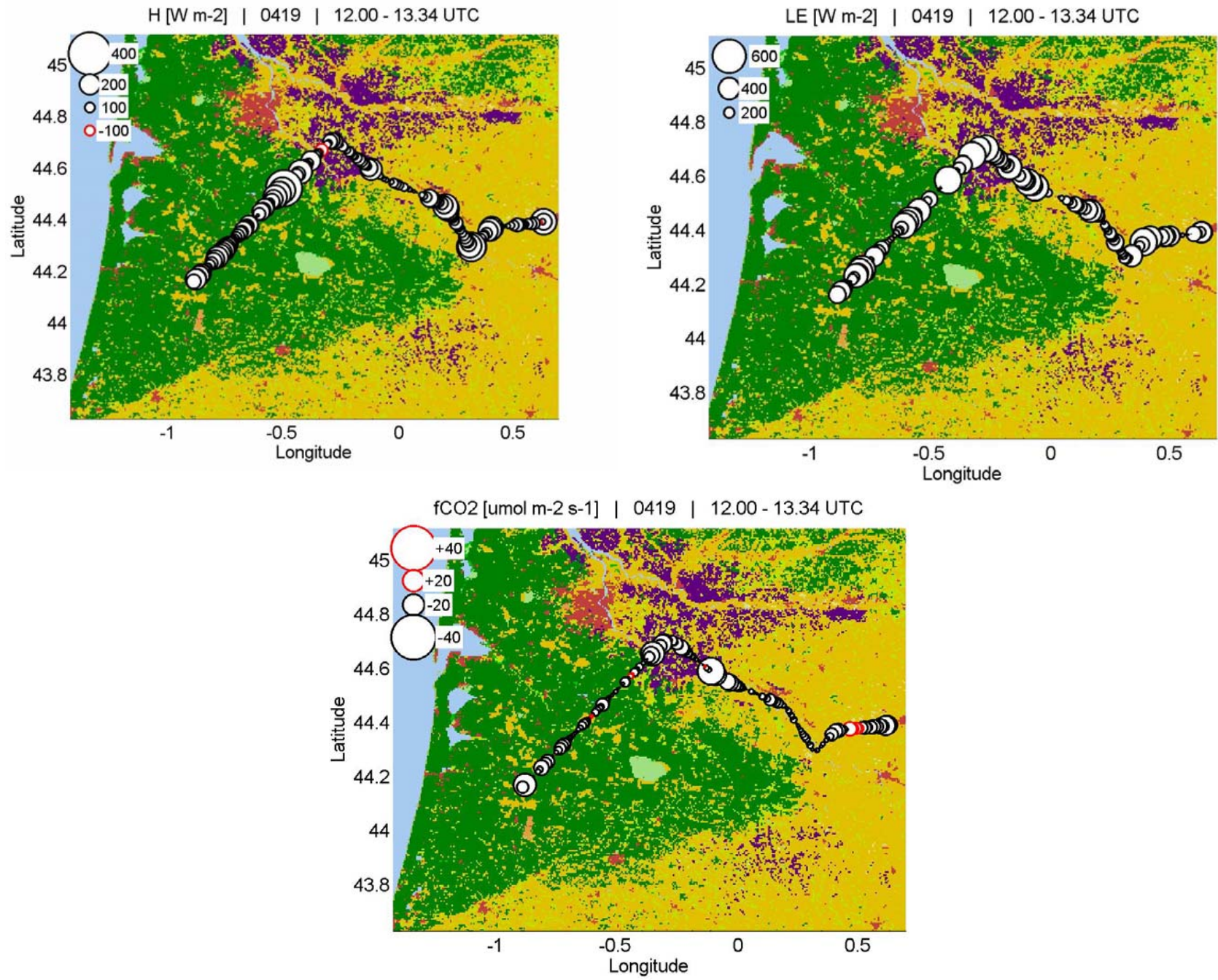

Fig. 4. Sky Arrow Ibimet measurement of sensible heat flux (a), latent heat flux (b) and $\mathrm{CO}_{2}$ flux (c) (data provided by IBIMET, Beniamino Gioli).

interaction with the surface fluxes was somewhat realistically simulated compared to the aircraft observations. This holds in particular for the large-scale features. Between the models there was considerable variation in the more fine scale structure of for instance the $\mathrm{CO}_{2}$ field. However, this raised hope that the meso-scale models may provide adequate transport of $\mathrm{CO}_{2}$ and other tracers at high resolution, when further fine tuned.

The dynamic parameters at the synoptic scale (temperature and relative humidity at $2 \mathrm{~m}$ ) but also at the local scale (potential temperature at various sites) were also validated by Sarrat et al. (2007b). All models were able to simulate the surface meteorology reasonably well. Some discrepancies with observations were also noted such as a cold bias in the initial temperature at $2 \mathrm{~m}$. This could have been due to an error in the initialization, but these errors could also be caused by the failure of the land surface parameterization schemes to correctly reproduce the partitioning of fluxes at the surface. Some models consistently simulated too large latent fluxes, resulting in too low and too humid boundary layers. There appeared no clear signal in the statistics of the bias during the diurnal cycle. The importance of entrainment at the top of the boundary layer was earlier noted Vila-Guerau et al. (2004) and lack of adequate parameterization may have contributed to the failure of some of the models to correctly estimate the boundary layer height.

Further work of Ahmadov et al. (2007) and Sarrat et al. (2007a) presents new simulations of specific events of the campaigns and shows significant improvement of model performance when elements of the land surface energy balance are better calibrated and simulated. Ahmadov et al. (2007) highlighted the complexity of the three dimensional structure that arises from meso-scale flows. They introduced WRFVPRM as a new modeling system that couples a diagnostic 

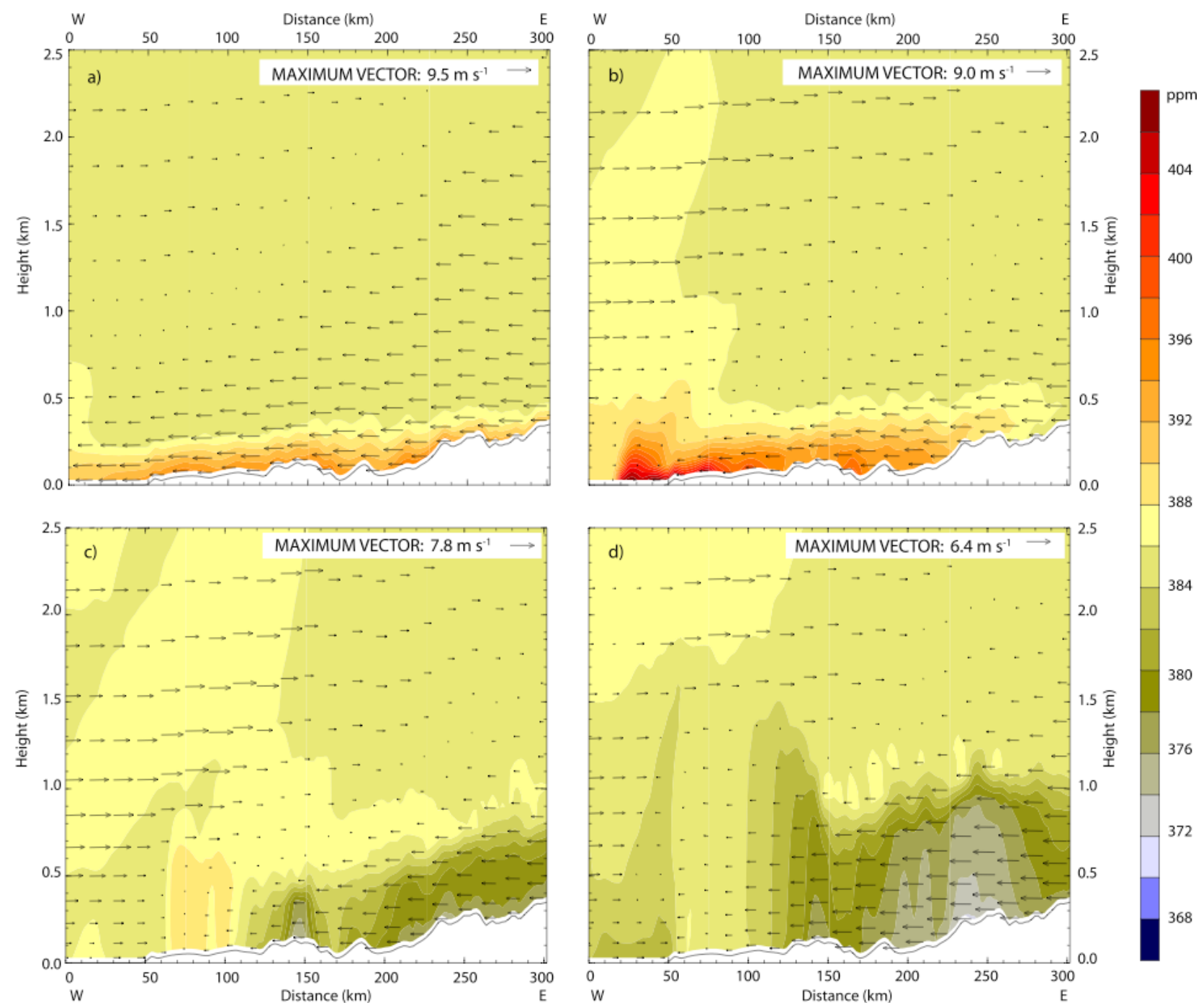

Fig. 5. $\mathrm{CO}_{2}$ distribution and wind vectors on the vertical plane along $44^{\circ} 25^{\prime} \mathrm{N}, 00^{\circ} 34^{\prime} \mathrm{W}$ for the 27 May case, at (a) 0000 , (b) 0600 , (c) 1000, and (d) 1400, (from Ahmadov et al., 2007).

biosphere model, a high-resolution emission inventory, and realistic boundary conditions from a global $\mathrm{CO}_{2}$ transport model with a weather forecasting model in order to simulate fluxes and concentrations of $\mathrm{CO}_{2}$ at high spatial and temporal resolution. They applied the modeling tool for two different days of the CERES 2005 regional experiment, with different conditions in both meteorology and biospheric activity. Due to its high spatial resolution the model captured meso-scale transport processes such as the sea-land breeze circulation. Figure 5d shows the horizontal distribution of near-surface $\mathrm{CO}_{2}$ and wind vectors at $14 \mathrm{~h}$ on 27 May 2003. Over the shore an area the wind convergence can be seen as well as a large area of enhanced $\mathrm{CO}_{2}$. This area extends to a few tens of kilometers inland, where strong decrease of $\mathrm{CO}_{2}$ starts and covers almost all of the eastern part of the region.
Over the ocean, near the coastline a turning of the low-level winds from southerly to south- westerly toward the coastline is found, which is clear evidence of the afternoon sea breeze. An interesting feature in the $\mathrm{CO}_{2}$ distribution is the patch of relatively low concentration over the coastal ocean, which can also be recognized in the western part of Fig. 5d. This plume did not yet arrive at this latitude at 1000 (Fig. 5c). The low $\mathrm{CO}_{2}$ patch originates from photosynthesis over the vegetated part of the domain.

Although the exact magnitude and direction of the sea breeze circulation was not always simulated perfectly, the main flow patterns were. Ahmadov et al. (2007) concluded that measurements made at coastal stations do not always see large-scale representative $\mathrm{CO}_{2}$ signals in onshore air flows, but that in cases of a sea breeze circulation the 
spatio-temporal patterns show a strong meso-scale character. This conclusion echoes the conjecture made by van der Molen and Dolman (2007) that some of the data used in large scale inversions may be subject to what we could call "mesoscale rectification effects".

Following this work Ahmadov et al. (2009) show how only the meso-scale models as WRF are able to simulate well the diurnal course of $\mathrm{CO}_{2}$ concentrations. This is an important issue, as this makes it in principle possible to start using the full information of the diurnal cycle in the observations. Lower resolution models are not quite capable of following the meso-scale perturbations caused by local topography and meso-scale dynamic processes. They ran WRF-VPRM for the period covering the intensive period of the CERES experiment, using the $\mathrm{CO}_{2}$ fields from the global model LMDZ for initialization and lateral boundary conditions. The comparison of modeled $\mathrm{CO}_{2}$ concentration time series against observations at the Biscarosse tower and against output from two global models - LMDZ and TM3 - clearly revealed that WRF-VPRM can capture the measured $\mathrm{CO}_{2}$ signal much better than the global models with lower resolution. Also the diurnal variability of the atmospheric $\mathrm{CO}_{2}$ field caused by recirculation of nighttime respired $\mathrm{CO}_{2}$ is simulated by WRFVRPM reasonably well. Analysis of the nighttime data indicates that with high resolution modeling tools such as WRFVPRM a large fraction of the time periods that are impossible to utilize in global models, can be used quantitatively and help constraining respiratory fluxes.

Tolk et al. (2008) used the meso-scale modeling system RAMS (Pielke et al., 1982) to further quantify the errors that arise from neglecting the 3-dimensional nature of the flow such as noted by Ahmadov et al. $(2007,2009)$ and Sarrat et al. (2007b). They defined the representation error in relation to the values of $\mathrm{CO}_{2}$ concentration in a $2 \mathrm{~km}$ resolution run with the mean value at a coarser resolution of 10, 20, 50 and $100 \mathrm{~km}$. They found that representation errors are caused by variations in topography, specific meso-scale circulations such as sea breezes and flux variability of the land surface. Note that the scale of the latter is smaller (meso-gamma) compared to the scale of the sea breezes (meso-beta). During the day, the sea breeze, leading to a small band of convergent flow where large errors arose, caused the largest representation errors. At night unresolved topography in the low resolution runs caused substantial errors due to accumulation of respired $\mathrm{CO}_{2}$.

The April 2007 campaign was simulated with the mesoscale model Meso-NH (Sarrat et al., 2009). This study shows how aircraft observations of $\mathrm{CO}_{2}$ concentration can be used to identify surface modeling errors and to calibrate the $\mathrm{CO}_{2}$ components of the surface model, particularly the LAI. They show also the improvement of the atmospheric $\mathrm{CO}_{2}$ simulation highly dependent of the on-line coupled surface scheme and its characteristics such as LAI.

\subsection{Inversion modelling}

The forward modeling discussed in the previous section has shown how spatially complex patterns of $\mathrm{CO}_{2}$ distribution can arise as a result from meso-scale atmospheric perturbations. Filtering out these perturbations from observational data has been the norm when site data are used in large scale inversions (e.g. Gurney et al, 2006). However as, for instance suggested in Ahmadov et al. (2009) and Gerbig et al. (2009), the variability in atmospheric concentration could also be used to put realistic constraints on surface inversions at regional scale. The prime requirement for this to be successful is a good simulation of the 3-D flow fields. However, even when this is achieved providing adequate a priori fields still remains a challenge.

In order to estimate the transport model error in the simulation of $\mathrm{CO}_{2}$ concentrations, Lavaux et al. (2008) studied the characteristics of a statistical ensemble of meso-scale simulations. Their ensemble consisted of ten members and a reference simulation. The ensemble of simulations was created by perturbing the initial and boundary conditions. The resulting ensemble represents then the model dependence on the boundary conditions which is a part of the model uncertainty (not including the intrinsic error of the mesoscale model itself). The variance of the ensemble was estimated over the domain, with associated spatial and temporal correlations. On the horizontal plane, the calculated variance of $\mathrm{CO}_{2}$ of the ensemble followed the discontinuities of the meso-scale structures during the day, but remained locally driven during the night. This corresponds with the analysis of Tolk et al. (2008) who found a similar covariance. In the vertical, the surface layer variance of $\mathrm{CO}_{2}$ showed large correlations with the upper levels in the boundary layer $(>0.6)$, down to 0.4 with the low free troposphere. Large temporal correlations were found during the afternoon ( $>0.5$ for several hours), that were reduced during the night. Using the ensemble to back calculate the fluxes, they found that the posterior error reduction on the inverted $\mathrm{CO}_{2}$ fluxes showed a predominance of the temporal over the spatial correlations when using tower-based $\mathrm{CO}_{2}$ concentration observations.

In a further study, Lavaux et al. (2009) use observations of the CERES campaigns to derive correction on a priori fluxes modeled by the ISBA-A-gs (Calvet et al., 1998). They used concentration measurements from the two tall towers in CERES 2007 to derive a correction for the fluxes, which were then subsequently validated by observations from eddy covariance towers and an aircraft (Gioli et al., 2006). They found a significant error reduction compared to the prior estimates of land surface fluxes. This error reduction also applied to the time evolution of the fluxes, which was substantially improved by the inversion. 


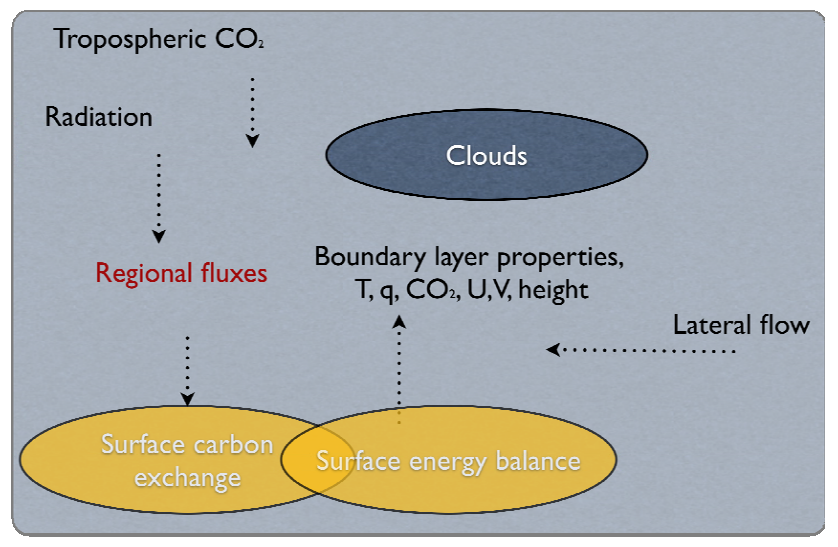

Fig. 6. Schematic diagram showing the variables and process involved in determining the regional carbon balance.

\section{Discussion and conclusion}

The CERES experiment and associated modeling improved our understanding of variations in $\mathrm{CO}_{2}$ concentration at the regional scale. The papers in this special issue bear witness to that. Figure 6 shows the interrelationships, and potential for feedbacks that are involved in studying the regional exchange of $\mathrm{CO}_{2}$. Experimentally the three campaigns were successful. The combination of high accuracy concentration measurements from both aircraft and tall towers proved to yield the required data. Concentration fields were used in the analysis of specific events (Dolman et al., 2006), but also for validation of mesoscale models (Sarrat et al., 2007a, b, 2009; Ahmadov et al., 2007, 2009). The flux data both for surface energy balance and $\mathrm{CO}_{2}$ exchange, obtained from several vegetation types proved essential data for calibrating the land surface schemes (e.g. Ahmadov et al., 2007) and for investigating and understanding fundamental differences in sequestration capacities Jarosz et al. (2009) and Stella et al. (2009). While observations on additional sites were only obtained during the experimental campaigns, the backbone of sites was part of the CarboEurope network of sites and these potentially allow for further studies involving question of representability and interannual variation.

The flux aircraft allowed repeated sampling of the same transect (forest, agriculture) under various environmental conditions. Although there are still issues requiring further investigation, such as the accurate quantification of the vertical flux divergence associated to the sign of the entrainment fluxes at the boundary layer top (Vila de Arellano et al., 2004), and temporal scale sampling issues associated to very low frequency energy and mass carrying turbulent eddies (Vickers and Mahrt, 2006), the technology used in these aircraft is by now becoming reliable and robust enough to be used in field experiments. Obtaining regional flux estimates provided not only for the development of relatively simple scaling techniques (Miglietta et al., 2007) but also gave the first inverse models at regional scale independent validation data (Lavaux et al., 2009) and provided key input into the analysis of the 2005 campaign (Dolman et al., 2006). Miglietta et al. (2009) furthermore show how the data can be used to validate remote sensing based estimations of sensible and latent heat at the regional scale.

At the start of the project the intercomparison showed agreement of several atmospheric variables with observations, albeit within relatively large errors (Sarrat et al., 2007a). These errors were attributed to differences in the surface parameterizations, that were subsequently better calibrated, with improvement in the model results as a consequence. The experience with CERES models shows however that considerable effort still needs to be put into calibrating the surface schemes, as they have direct impact on the input of energy, moisture and carbon fluxes in the boundary layer. Overall, the models appear to be capable of simulating the large scale (meso-beta) dynamics of the region, but in the fine detail, like the precise horizontal and vertical $\mathrm{CO}_{2}$ field differences between the models still exist. These errors translate directly into transport uncertainty, when the forward simulations are used in inverse mode. Quantification of this uncertainty, including that of inadequate boundary layer height modeling, still remains a major challenge for state of the art mesoscale models.

One of the key question that evolved from executing the CERES campaigns was how much variability there is present in the atmospheric $\mathrm{CO}_{2}$ signal and how much of this variability can be explained by meso-scale processes and the interaction of the land surface with the atmosphere. As documented in Dolman et al. (2006) the variability can be large and substantial, and can only be understood when meso-scale processes such as sea breezes, differences in land surface uptake patterns and 3-D flow fields are analyzed together. The progress in developing and testing the meso-scale models that have $\mathrm{CO}_{2}$ included has much been improved during the course of this project (e.g. Sarrat et al., 2007; Ahmadov et al., 2009; ter Maat et al., 2009; Tolk et al., 2008). However, the work also showed up errors in mass balance closure in the models that needed to be corrected before realistic $\mathrm{CO}_{2}$ fields could be obtained (Meesters et al., 2008). The models are now capable to realistically simulate diurnal patterns of carbon uptake and the associated atmospheric variability. Further progress in this area can be expected when the meso-scale models, probably with dynamical phenology models incorporated, will start to tackle questions of regional variability at seasonal time scales. Sarrat et al. (2009) show the importance of correctly representing leaf area development in mesoscale models for the 2007 campaign, while earlier results (Dolman et al., 2006) showed the importance of correctly specifying for instance the difference in winter and summer crops.

The observation that the source areas of receptor points like tall towers vary strongly dynamically, suggest that analysis of the meso-scale flow field around tall towers is a real 
critical item in a quality assessment of these towers (e.g. van der Molen and Dolman, 2006; Gerbig et al., 2009). Progress in using the modelled flow fields with observed concentration in a regional inversion framework has been slow, but significant (e.g. Lavaux et al., 2009). Further work using several techniques such as MLEF (e.g. Peters et al., 2007) or Lagrangian tracer models (Lin et al., 2004) is needed to show the viability of this approach at regional scale.

Figure 6 shows not only the surface and atmospheric properties that need to be observed and modeled, but arguably more important, also the potential for feedback between these properties. This is what makes mesoscale modeling indispensable, maybe even despite its current shortcomings, for understanding the regional carbon fluxes. Most of the analysis in CERES has concentrated on days with no cloud and relatively "easy" boundary layer development. The impact of surface heterogeneities on for instance cloud development has not been studies, and it can be argued that for seasonal prediction or assimilation of $\mathrm{CO}_{2}$ fluxes, such studies are urgently needed. This is a major next step.

Overall the papers in this special issue show how the combination of a highly dense observation network, coupled with advanced meso-scale atmospheric models leads to a fruitful analysis of regional carbon fluxes. During the experiment novel techniques such as Langrangian (constant pressure) balloons were used to track air masses. As already noted, in the 2007 campaigns the experiment was extended to include several new remote sensing techniques from aircraft. Without an integrated experiment such as CERES, these innovations would not have been possible. The data will become available at http://carboregional.mediasfrance.org/.

Acknowledgements. This work was supported by the EU project CarboEurope-IP, contract GOCE-CT2003-505572. We also thank the large number of people who assisted in the field during the campaigns and who were supported by individual complementary grants.

Edited by: A. Arneth

\section{References}

Ahmadov, R., Gerbig, C., Kretschmer, R., et al.: Meso-scale covariance of transport and $\mathrm{CO}_{2}$ fluxes: evidence from observations and simulations using the WRF-VPRM coupled atmosphere-biosphere model, J. Geophys. Res.-Atmos., 112, D22107, doi:10.1029/2007JD008552, 2007.

Ahmadov, R., Gerbig, C., Kretschmer, R., Körner, S., Rödenbeck, C., Bousquet, P., and Ramonet, M.: Comparing high resolution WRF-VPRM simulations and two global $\mathrm{CO}_{2}$ transport models with coastal tower measurements of $\mathrm{CO}_{2}$, Biogeosciences, 6, 807-817, 2009,

http://www.biogeosciences.net/6/807/2009/.

André, J. C., Goutorbe, J. P., and Perrier, A.: A hydrologic atmospheric experiment for the study of water budget and evaporation flux at the climatic scale, B. Am. Meteorol. Soc., 67, 138-144, 1986.

Andreae, M. O., Artaxo, P., Brandao, C., et al.: Biogeochemical cycling of carbon, water, energy, trace gases, and aerosols in Amazonia: The LBA-EUSTACH experiments, J. Geophys. Res., 107(D20), 8066, doi:10.1029/2001JD000524, 2002.

Calvet, J.-C., Noilhan, J., Roujean, J.-L., Bessemoulin, P., Cabelguenne, M., Olioso, A., and Wigneron, J.-P.: An interactive vegetation SVAT model tested against data from six contrasting sites, Agr. Forest Meteorol., 92, 73-95, 1998.

Denning, A. S., Randall, D. A., Collatz, G. J., and Sellers, P. J.: Simulations of terrestrial carbon metabolism and atmospheric $\mathrm{CO}_{2}$ in a general circulation model, 2, Simulated $\mathrm{CO}_{2}$ concentrations, Tellus B, 48(4), 543-567, 1996.

Denning, S., Nicholls, M., Prihodko, L., Baker, I., Vidale, P.L., Davis, K., and Bakwin, P.: Simulated variations in atmospheric $\mathrm{CO}_{2}$ over a Wisconsin forest using a coupled ecosystematmosphere model, Glob. Change Biol., 9, 1241-1250, 2003.

Dolman, A. J., Noilhan, J., Durand, P., et al.: The CarboEurope regional experiment strategy, B. Am. Meteorol. Soc., 87(10), 1367-1379, 2006.

Dolman, A. J., Freibauer, A., and Valentini, R.: The Continental Scale Greenhouse Gas balance of Europe, Springer Ecological Series 203, Springer, New York, 390 pp., 2008.

Gerbig, C., Lin, J., Wofsy, S., Daube, B., Andrews, A., Stephens, B., Bakwin, P., and Grainger, A.: Toward constraining regional scale fluxes of $\mathrm{CO}_{2}$ with atmospheric observations over a continent: 1, Observed spatial variability from airborne platforms, J. Geophys. Res., 108(D24), 4756, doi:10.1029/2002JD003018, 2003.

Gerbig, C., Dolman, A. J., and Heimann, M.: On observational and modelling strategies targeted at regional carbon exchange over continents, Biogeosciences Discuss., 6, 1317-1343, 2009,

http://www.biogeosciences-discuss.net/6/1317/2009/.

Gioli, B. A. F. M., Martino, D. B., Hutjes, R. A., Dolman, H. A. J., Lindroth, A., Schumacher, M., Sanz, M., Manca, G., Peressotti, A., and Dumas, E. J.: Comparison between tower and aircraft-based eddy covariance fluxes in five European regions, Agr. Forest Meteorol., 127, 1-16, 2004.

Gurney, K., Law, R. M., Rayner, P., et al.: Towards robust regional estimates of $\mathrm{CO}_{2}$ sources and sinks using atmospheric transport models, Nature, 415, 626-630, 2002.

Habets, F., Boone, A., Champeaux, J.-L., Etchevers, P., Franchisteguy, L., Leblois, E., Ledoux, E., Le Moigne, P., Martin, E., and Morel, S.: The SAFRAN-ISBA-MODCOU hydrometeorological model applied over France, J. Geophys. Res.-Atmos., 113, D06113, doi:10.1029/2007JD008548, 2008.

Jarosz, N., Béziat, P., Bonnefond, J. M., Brunet, Y., Calvet, J. C., Ceschia, E., Elbers, J. A., Hutjes, R. W. A., and Traullé, O.: Effect of land use on carbon dioxide, water vapour and energy exchange over terrestrial ecosystems in Southwestern France during the CERES campaign, Biogeosciences Discuss., 6, 27552784, 2009, http://www.biogeosciences-discuss.net/6/2755/2009/.

Lauvaux, T., Pannekoucke, O., Sarrat, C., Chevallier, F., Ciais, P., Noilhan, J., and Rayner, P. J.: Structure of the transport uncertainty in mesoscale inversions of $\mathrm{CO}_{2}$ sources and sinks using ensemble model simulations, Biogeosciences Discuss., 5, 48134846, 2008, 
http://www.biogeosciences-discuss.net/5/4813/2008/.

Meesters, A. G. C. A., Tolk, L. F., and Dolman, A. J.: Mass conservation above slopes in the Regional Atmospheric Model ling System (RAMS), Environ. Fluid Mech., 8(3), 239-248, 2008.

Miglietta, F., Gioli, B., Hutjes, R. W. A., and Reichstein, M.: Net regional ecosystem $\mathrm{CO}_{2}$ exchange from airborne and groundbased eddy covariance, land-use maps and weather observations, Glob. Change Biol., 13, 548-560, 2007.

Miglietta, F., Gioli, B., Brunet, Y., Hutjes, R. W. A., Matese, A., Sarrat, C., and Zaldei, A.: Sensible and latent heat flux from radiometric surface temperatures at the regional scale: methodology and validation, Biogeosciences Discuss., 6, 1945-1978, 2009 , http://www.biogeosciences-discuss.net/6/1945/2009/.

Nicholls, M., Prihdodko, S. D., and L., Vidale, P.-L., Baker, I., Davis, K., and Bakwin, P.: A multiple-scale simulation of variations in atmospheric carbon dioxide using a coupled biosphere-atmospheric model, J. Geophys. Res., 109, D18117, doi:10.1029/2003JD004482, 2004.

Peters, W., Jacobson, A., Sweeney, C., Andrews, A., Conway, T., Masarie, K., et al.: An atmospheric perspective on North American carbon dioxide exchange: CarbonTracker, P. Natl. Acad. Sci., 104(48), 18925-18930, 2007.

Pielke, R. A., Cotton, W. R., Walko, R. L., Tremback, C. J., Lyons, W. A., Grasso, L. D., Nicholls, M. E., Moran, M. D., Lee, D. A. W. T. J., and Copeland, J. H.: A Comprehensive Meteorological Modelling System Rams, Meteorol. Atmos. Phys., 49, 69-91, 1992.

Rascher, U., Agati, G., Alonso, L., Cecchi, G., Champagne, S., Colombo, R., Damm, A., Daumard, F., de Miguel, E., Fernandez, G., Franch, B., Franke, J., Gerbig, C., Gioli, B., Gómez, J. A., Goulas, Y., Guanter, L., Gutiérrez-de-la-Cámara, Ó., Hamdi, K., Hostert, P., Jiménez, M., Kosvancova, M., Lognoli, D., Meroni, M., Miglietta, F., Moersch, A., Moreno, J., Moya, I., Neininger, B., Okujeni, A., Ounis, A., Palombi, L., Raimondi, V., Schickling, A., Sobrino, J. A., Stellmes, M., Toci, G., Toscano, P., Udelhoven, T., van der Linden, S., and Zaldei, A.: CEFLES2: the remote sensing component to quantify photosynthetic efficiency from the leaf to the region by measuring sun-induced fluorescence in the oxygen absorption bands, Biogeosciences Discuss., 6, 2217-2266, 2009, http://www.biogeosciences-discuss.net/6/2217/2009/.

Sarrat, C., Noilhan, J., Lacarrère, P., Donier, S., Lac, C., Calvet, J.-C., Dolman, A., Gerbig, C., Neininger, B., Ciais, P., Paris, J., Boumard, F., Ramonet, M., and Butet, A.: Atmospheric $\mathrm{CO}_{2}$ modeling at the regional scale: Application to the CarboEurope Regional Experiment, J. Geophys. Res., 395, 112, D12105, doi:10.1029/2006JD008107, 2007a.

Sarrat, C., Noilhan, J., Dolman, A. J., Gerbig, C., Ahmadov, R., Tolk, L. F., Meesters, A. G. C. A., Hutjes, R. W. A., Ter Maat, H. W., Pérez-Landa, G., and Donier, S.: Atmospheric $\mathrm{CO}_{2}$ modeling at the regional scale: an intercomparison of 5 meso-scale atmospheric models, Biogeosciences, 4, 1115-1126, 2007, http://www.biogeosciences.net/4/1115/2007/.
Sarrat, C., Noilhan, J., Lacarrère, P., Ceschia, E., Ciais, P., Dolman, A. J., Elbers, J. A., Gerbig, C., Gioli, B., Lauvaux, T., Miglietta, F., Neininger, B., Ramonet, M., Vellinga, O., and Bonnefond, J. M.: Mesoscale modelling of the $\mathrm{CO}_{2}$ interactions between the surface and the atmosphere applied to the April 2007 CERES field experiment, Biogeosciences, 6, 633-646, 2009, http://www.biogeosciences.net/6/633/2009/.

Skamarok, W. C.; Klemp, J. B., Dudhia, J., Gill, D. O., Barker, D. M., Wang, W., and Powers, J. G.: A description of the advanced research WRF version 2, NCAR Technical Note, 468+STR, available at http://www.mmm.ucar.edu/wrf/ users/docs/arwv2.pdf, last access on 15 June 2009, 2005.

Stephens, B. B., Gurney, K. R., Tans, P. P., et al.: Weak northern and strong tropical land carbon uptake from vertical profiles of atmospheric $\mathrm{CO}_{2}$, Science, 316, 1732-1735, 2007.

Schmitgen, S., Gei, H., Ciais, P., Neininger, B., Brunet, Y., Reichstein, M., Kley, D., and Volz-Thomas, A.: Carbon dioxide uptake of a forested region in southwest France derived from airborne $\mathrm{CO}_{2}$ and $\mathrm{CO}$ measurements in a quasi-lagrangian experiment, $\mathrm{J}$. Geophys. Res., 109(D14), D14302, doi:10.1029/2003JD004335, 2004.

Stella, P., Lamaud, E., Brunet, Y., Bonnefond, J.-M., Loustau, D., and Irvine, M.: Simultaneous measurements of $\mathrm{CO}_{2}$ and water exchanges over three agroecosystems in South-West France, Biogeosciences Discuss., 6, 2489-2522, 2009, http://www.biogeosciences-discuss.net/6/2489/2009/.

Ter Maat, H. W. and Hutjes, R. W. A.: Simulating carbon exchange using a regional atmospheric model coupled to an advanced landsurface model, Biogeosciences Discuss., 5, 4161-4207, 2008, http://www.biogeosciences-discuss.net/5/4161/2008/.

Tolk, L. F., Meesters, A. G. C. A., Dolman, A. J., and Peters, W.: Modelling representation errors of atmospheric $\mathrm{CO}_{2}$ mixing ratios at a regional scale, Atmos. Chem. Phys., 8, 6587-6596, 2008 , http://www.atmos-chem-phys.net/8/6587/2008/.

Van der Molen, M. K. and Dolman, A. J.: Regional carbon fluxes and the effect of topography on the variability of atmospheric $\mathrm{CO}_{2}$, J. Geophys. Res., 112, D01104, doi:10.1029/2006JD007649, 2007.

Vickers, D. and Mahrt, L.: A solution for flux contamination by mesoscale motions with very weak turbulence, Bound.-Lay. Meteorol., 118, 431-447, 2006.

Vila-Guerau de Arellano, J., Gioli, B., Miglietta, F., Jonker, H., Baltink, H., Hutjes, R., and Holtslag, A.: Entrainment process of carbon dioxide in the atmospheric boundary layer, J. Geophys. Res., 109, D18110, doi:10.1029/2004JD004725, 2004. 